\title{
Role of striated penile muscles in penile reflexes, copulation, and induction of pregnancy in the rat
}

\author{
B. D. Sachs \\ University of Connecticut, Department of Psychology, Storrs, Connecticut 06268, U.S.A.
}

\begin{abstract}
Summary. In 4 experiments, various striated penile muscles of the rat were excised. Without the ischiocavernosus (IC) muscles no dorsiflexions ('flips') of the glans penis occurred during ex copula reflex tests, but erections were unaffected. In attempted copulation, males lacking the IC muscles rarely gained intromission, apparently because dorsiflexion of the glans penis is necessary for penetration of the vagina. Nonetheless some males lacking the IC muscles displayed the gross motor pattern of intromission and ejaculated, but rarely within the vagina. Males lacking the bulbocavernosus (BC) and levator ani (LA) muscles were incapable of developing intense erections ('cups') in ex copula tests, but they did have lesser erections, probably due to vascular action. Males with excised BC and LA muscles displayed normal copulatory behaviour, including intromission and intravaginal ejaculation, but only $1 / 15$ females mated to these males became pregnant. The infertility of the males was attributed in part to their inability to form the penile cup, which caused them to withdraw a larger portion of the seminal plug from the vagina and, presumably, prevented the plug from being tightly lodged against the cervix. In male rats copulation apparently requires co-ordination of the penile vasculature with the contraction of separate groups of striated penile muscles, each having a distinct contribution to the integrated pattern of copulation and, ultimately, to the male's fertility.
\end{abstract}

\section{Introduction}

The striated penile muscles of rodents are presumed to have a role in the male's sexual activity. This assumption lacks direct evidence, but derives from at least three kinds of indirect evidence: (1) the anatomy of the muscles relative to the penis suggests a role in penile actions (Plate 1); (2) the homologous muscles of several other mammalian species have been implicated in penile erection and ejaculation (Hart \& Kitchell, 1966; Hart, 1972; Beckett, Hudson, Walker, Vachon \& Reynolds, 1972; Beckett, Hudson, Walker, Reynolds \& Vachon, 1973; Beckett, Walker, Hudson, Reynolds \& Vachon, 1974; Beckett, Purohit \& Reynolds, 1975; Purohit \& Beckett, 1976); and (3) rat genital muscles (Wainman \& Shipounoff, 1941; Cihák, Gutmann \& Hanzliková, 1970) and their central neural innervation (Breedlove \& Arnold, 1980, 1981; Jordan, Breedlove \& Arnold, 1982) are sexually dimorphic and androgen sensitive. However, to permit functional interpretation of research developments on the somatic (Schrøder, 1980; Breedlove \& Arnold, 1980, 1981; Jordan et al., 1982) and autonomic (Dail \& Evan, 1974; McConnell, Benson \& Wood, 1979) innervation of the rat's genital structures, direct evidence on the role(s) of striated penile muscles is needed. In the experiments reported here the effects of removing these muscles on sexual behaviour and fertility were observed. 
The nomenclature of the perineal muscles of rodents is nearly as uncertain as their function, due in part to unresolved issues of homology and ontogeny (Hayes, 1965; Cihák et al., 1967, 1970). However, these issues do not bear upon the concerns of this paper, and I have adopted the conventional terminology (Greene, 1935): $\mathrm{m}$. ischiocavernosus, $\mathrm{m}$. bulbocavernosus $(=\mathrm{m}$. bulbospongiosus), and $\mathrm{m}$. levator ani ( $=\mathrm{m}$. bulbocavernosus dorsalis (Hayes, 1965), $=\mathrm{m}$. sphincter ani externus (Hebel \& Stromberg, 1976)).

\section{Experiment 1}

\section{Materials and Methods}

Hooded Long-Evans rats were received at 70 days of age from Charles River Breeding Laboratories (Wilmington, Massachusetts). The test males were selected from this group on the basis of their performance in screening tests (see below).

\section{Procedure}

Housing. Females were housed in groups of 4 or 5 in wire mesh cages $(80 \times 18 \times 21 \mathrm{~cm})$. Males were individually housed in wire mesh cages $(38 \times 18 \times 21 \mathrm{~cm})$, except for 5 days after surgery when they were housed on pine shavings in plastic tubs $(45 \times 24 \times 15 \mathrm{~cm})$. Colony lights were off from 10:00-22:00 h. Pelleted diet and water were always available.

Behavioural tests. For the ex copula penile reflex tests, males were placed in the supine position with head and anterior torso enclosed in a loosely fitting plastic cylinder (Hart, 1968; Sachs \& Garinello, 1978). Additional restraint was provided by a strap wound around the rat's midsection and anchored to the board below. The rat's hindlegs were manually held throughout the test, which was begun by retracting the penile sheath and maintaining it in that position by a wooden applicator held lightly against the posterior base of the glans penis in such a way as to keep the glans perpendicular to the rat's ventral surface.

The following responses were recorded via toe-activated buttons onto an event recorder: erections (distension and elongation of the glans penis), cups (intense erections in which the distal end of the glans flares to become more cup or bell-shaped than tubular), and flips (dorsiflexion of the glans, usually without erection).

For the copulation test, males were individually placed into glass chambers $(50 \times 30 \times 28$ $\mathrm{cm}$ ) littered with pine shavings. An oestrous female was placed with the male 5-10 min later. Oestrus was induced by injecting $50 \mu \mathrm{g}$ oestradiol benzoate approximately $48 \mathrm{~h}$ before testing and $1 \mathrm{mg}$ progesterone $4-6 \mathrm{~h}$ before testing.

The male's mounts (mount with foreleg palpation of female's flanks), intromission patterns (mounts ending with a single sharp pelvic fiexion and extension, the latter accompanied by quick withdrawal of the forelegs from the flanks), and ejaculatory patterns (like intromission patterns, but with longer pelvic flexion and slower pelvic extension and foreleg withdrawal) were recorded on an event recorder. The hit rate was derived from the no. of intromission patterns/(no. of mounts + no. of intromission patterns).

\section{Test schedule}

Screening. Forty-five males received 3 reflex tests and 3 copulation tests during a 7-day period. Reflex screening tests were terminated after the first reflex (invariably an erection) or after $20 \mathrm{~min}$, whichever came first. Copulation screening tests were stopped after the first intromission pattern or $15 \mathrm{~min}$ after the introduction of a receptive female, whichever came first.

Twenty-four males were selected on the basis of having responded with an erection and with an intromission pattern in 2 of the 3 reflex and copulation tests respectively. 


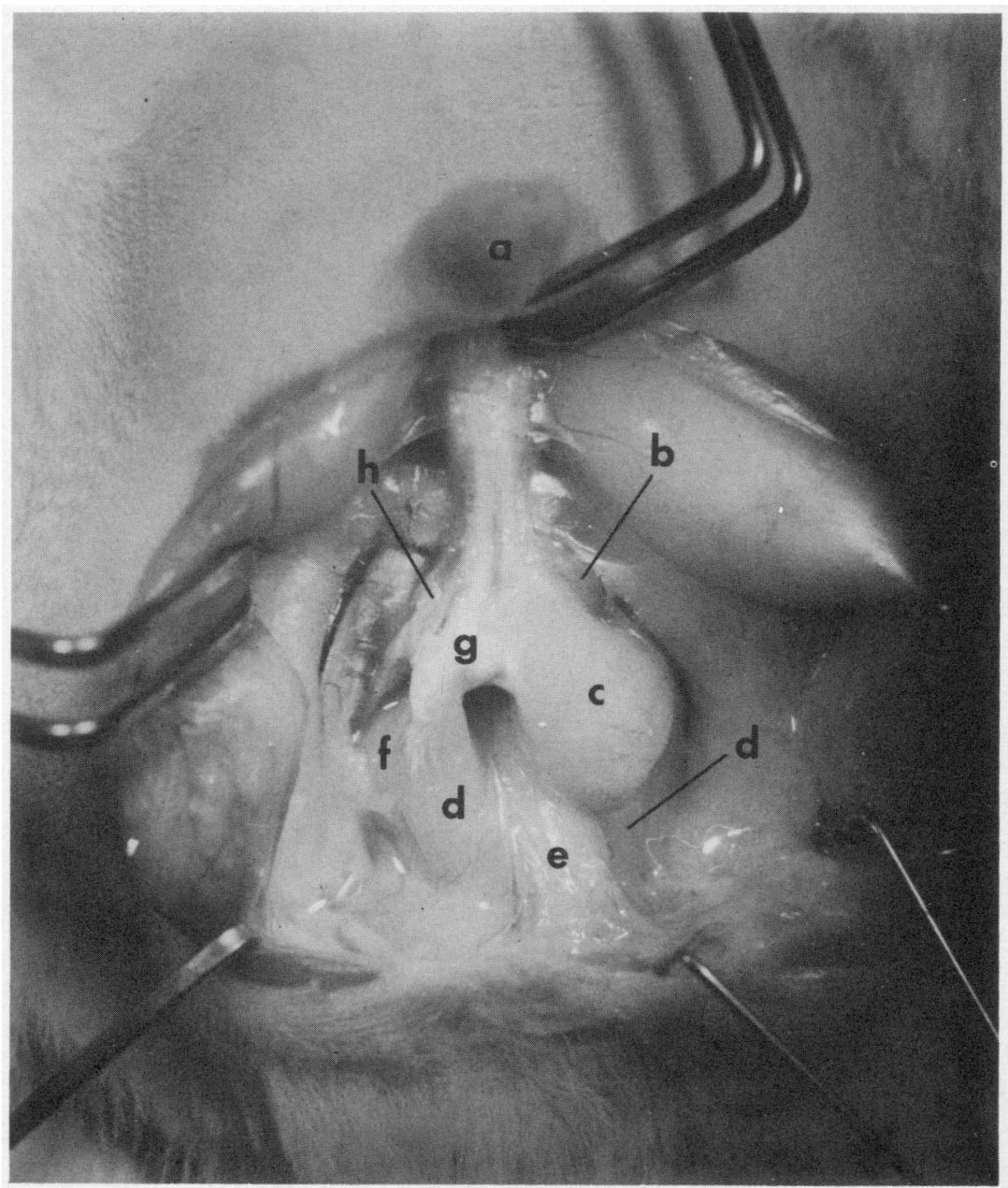

The striated muscles of the laboratory rat. The right bulbocavernosus and ischiocavernosus muscles have been removed, revealing the underlying structures; $a$, penile sheath: $b$. $m$. ischiocavernosus: $c, m$. bulbocavernosus; $d, m$. levator ani: e. rectum: $f$, bulbourethral gland: $g$. bulb of penis: h. crura of penis. 
Pre- and post-operative testing. Males received 2 reflex and 2 copulation tests during a 1-week period just before surgery.

For the copulation tests males were allowed $30 \mathrm{~min}$ in which to display an intromission pattern before a test was ended. If no intromission pattern had occurred within $15 \mathrm{~min}$, the first female was exchanged for another oestrous female. After the first intromission pattern observations continued for $30 \mathrm{~min}$ or, if an ejaculatory pattern occurred, until the resumption of copulation after ejaculation. In the reflex tests $30 \mathrm{~min}$ were allowed for the first penile response to occur, and tests continued for $15 \mathrm{~min}$ after the first response. The reflex tests were conducted 24-28 $\mathrm{h}$ after the preceding copulation test.

Beginning 10 days after surgery, tests identical to the preoperative test protocol were conducted. Statistical analyses were based on the second of each pair of tests and usually comprised one-way analyses of variance followed, if $P<0.05$, by Newman-Keuls tests for post-hoc comparisons between groups. However, for cups and flips, for which there were many zero entries, the nonparametric Kruskal-Wallis $(H)$ and Mann-Whitney $(U)$ tests were used.

\section{Assignment to groups}

The 24 males were randomly assigned to the 3 surgical treatment groups, with the constraint that the groups did not differ significantly with respect to the mean number of erections, cups or flips displayed in the second preoperative test.

\section{Surgery}

General. Males were anaesthetized with pentobarbitone sodium and chloral hydrate (Choloropent, Fort Dodge Laboratories, Fort Dodge, Iowa; $4 \mathrm{ml} / \mathrm{kg}$ body weight, i.p.) and the scrotum was shaved. A $2-3 \mathrm{~cm}$ midline incision was made in the skin beginning $1 \mathrm{~cm}$ posterior to the penile sheath and running caudally. Access to the muscles was facilitated by pushing the testes into the body cavity and then cutting and reflecting the fascia. Care was taken not to damage the bulbourethral glands.

At the conclusion of surgery Gelfoam (Upjohn, Kalamazoo, Michigan) was placed on the operated area, and the skin was sewn with silk sutures. The skin around the incision was swabbed with picric acid and neomycin sulphate ointment, and tetracycline $(8 \mathrm{mg}$ in $3 \mathrm{ml}$ $0.154 \mathrm{M}-\mathrm{NaCl}$ ) was injected s.c. Neomycin was applied daily for 5 days after surgery.

Group BLx: excision of $m$. bulbocavernosus and $m$. levator ani. The $\mathrm{m}$. levator ani was cut near its junctures with the $\mathrm{m}$. bulbocavernosus and, after cutting its fascial attachments to the rectum, it was removed. Then the bulbocavernosus muscle was cut away and removed from the penile bulb. Two of the 8 animals died.

Group ICx: excision of $m$. ischiocavernosus and crura. For these animals the skin incision was branched into a $\mathrm{Y}$ at its anterior end. The $\mathrm{m}$. ischiocavernosus forms a number of fascicles with the crura at the centre, and the dorsal portions are relatively inaccessible. Therefore, for an initial evaluation of the functions of this muscle, the ischiocavernosus and the underlying crura were clamped medially and transected slightly lateral to the clamp, as well as at the connection to the pelvic bone. The medial portion was tied with silk suture and cauterized before the clamp was removed.

Group $S x$ : sham excision. Half the males in this group had a straight incision; the other males received the $\mathrm{Y}$-shaped incision. The fascia overlying the muscles were cut and the incision was then sewn with sutures.

\section{Results}

The effects of penile muscle excision are summarized in Table 1. In ex copula tests, erections (without cups) were similar in all 3 groups $(F(2,19)=1 \cdot 48)$. However, the groups differed for 
the number of cups $(H=8 \cdot 50, P<0.02)$ and flips $(H=8 \cdot 52 ; P<0.02)$ displayed. Group BLx produced no cups and few flips, whereas Group ICx produced a normal number of cups but no penile flips.

The copulatory behaviour of Group BLx males was statistically indistinguishable from that of Group Sx animals. However, only $2 / 8$ of the Group ICx males displayed intromission patterns although they mounted often, resulting in low Hit Rate. Nonetheless, $2 / 8$ of the Group ICx males displayed the ejaculatory pattern, albeit after very long latencies ( 22 and $26 \mathrm{~min}$, respectively).

Table 1. Penile reflexes and copulatory behaviour in rats after excision of the striated penile muscles

\begin{tabular}{|c|c|c|c|c|c|c|}
\hline & \multicolumn{3}{|c|}{ Penile reflexes ex copula } & \multicolumn{3}{|c|}{ Copulatory behaviour } \\
\hline & Erections & Cups & Flips & $\begin{array}{l}\text { Intromission } \\
\text { patterns }\end{array}$ & $\begin{array}{l}\text { Ejaculation } \\
\text { latency (min) }\end{array}$ & Hit rate \\
\hline Group BLx & $12 \cdot 5 \pm 3 \cdot 1$ & $0.0 \pm 0.0^{*}$ & $2 \cdot 5 \pm 1 \cdot 1^{*}$ & $10 \cdot 5 \pm 2 \cdot 7$ & $3.8 \pm 0.8$ & $0.73 \pm 0.05$ \\
\hline Group ICx & $12 \cdot 2 \pm 4 \cdot 5$ & $6.0 \pm 3.0$ & $0.0 \pm 0.0^{*}$ & $2.1 \pm 1.5^{* *+}$ & $24.2 \pm 1.8^{* *}+$ & $0.08 \pm 0.06^{* *} \S$ \\
\hline Group Sx & $20 \cdot 0 \pm 3.0$ & $7 \cdot 5 \pm 1 \cdot 3$ & $12.9 \pm 2.4$ & $11.5 \pm 1.5$ & $5.3 \pm 0.6$ & $0.71 \pm 0.06$ \\
\hline
\end{tabular}

Values are means \pm s.e.m. Group BLx: $\mathrm{m}$. bulbocavernosus and $\mathrm{m}$. levator ani removed, $\mathrm{N}=6 ; \mathrm{Group}$ ICx: $\mathrm{m}$. ischiocavernosus and crura removed, $\mathrm{N}=8 ;$ Group $\mathrm{Sx}$ : sham operation, $\mathrm{N}=8$.

${ }^{*} P<0.01$ relative to Group Sx by Mann-Whitney test.

** $P<0.01$ relative to Group Sx by Newman-Keuls test.

+ Based on all males; if 5 non-intromitting males are excluded, values are $5 \cdot 7 \pm 3 \cdot 3$.

$\mp$ Based on 2 males that ejaculated.

$\S$ Based on 3 males that displayed intromission patterns.

\section{Discussion}

This experiment established that the bulbocavernous and/or levator ani muscles of the rat are essential for the formation ex copula of the intense erections called penile cups. However, lesser erections occur in undiminished number without these muscles. Since no other striated muscles are known to be involved in erection, systems not employing striated muscles may be able to effect partial erections in rats as in dogs and other animals (Purohit \& Beckett, 1976; Hart, 1983). Removal of the bulbocavernosus and levator ani muscles had no discernible effect on the gross appearance or measures of the male's copulatory behaviour, but more subtle effects cannot be ruled out (see Exp. 4).

Removal of the ischiocavernosus muscles and crurae precluded the occurrence of penile flips ex copula, and reduced sharply the occurrence of intromission patterns during copulation. Nonetheless, the ejaculatory pattern was eventually displayed by 2 males. These results suggest that ischiocavernosus-induced dorsiflexion of the glans may contribute to the detection of the vaginal orifice or the triggering of the hip flexion that initiates (and signals to the observer) the intromission pattern. The lack of effect of excision of $\mathrm{m}$. ischiocavernosus and crura on the occurrence of erections and cups ex copula suggests that these structures do not participate in these penile actions (but see Exp. 3).

\section{Experiment 2}

Copulation in rats is a succession of rapid events: intromissions last only $200-400 \mathrm{msec}$. The speed and the observer's perspective often do not permit detection of genital contact between male and female, but a variety of techniques have repeatedly confirmed that, in general, the gross motor patterns of the male rat reliably signal the accompanying genital actions (Sachs \& 
Barfield, 1976). In some circumstances, however, the correspondence between the male's bodily actions and genital events may break down (Pollak \& Sachs, 1976; O'Hanlon, Meisel \& Sachs, 1981). For example, although the Group BLx males in Exp. 1 displayed normal intromission and ejaculatory patterns, they may not have achieved vaginal insertion. Conversely, the Group ICx males rarely displayed intromission patterns, but they could have penetrated the vagina more often than they appeared to. This experiment was designed to examine these points.

\section{Materials and Methods}

The males and females from Exp. 1 were used.

\section{Procedure}

These tests were given 4-10 days after the last copulation test of Exp. 1. The method for verifying penile insertion was developed by O'Hanlon et al. (1981). Four colours of non-toxic, water-soluble, tempera paint were mixed with water to a toothpaste consistency, and then loaded into disposable $1 \mathrm{ml}$ syringes that had no needles attached. Eight hormonally-induced oestrous females ( 2 for each colour) had $0.15 \mathrm{ml}$ paint injected deep into the vagina. Each female was then placed with a non-test male who was allowed to achieve intromission, thereby distributing the paint throughout the vagina.

Females were then placed one at a time with a test male. Following each intromission pattern the male was removed and the glans penis was extruded and inspected for paint. The presence of paint indicated that penile intromission had occurred; the absence of paint suggested that the preceding event was an extravaginal intromission pattern (Pollak \& Sachs, 1976). The latter presumption was tested by immediately placing the female with a non-test male to ensure that his glans was paint-covered after intromission. Following each inspection of the glans the test male was returned to the testing chamber with a female with a different intravaginal colour. After every 3-4 intromissions a female was injected with additional paint. This procedure continued until the test male displayed an ejaculatory pattern, or for $10 \mathrm{~min}$ after the first intromission pattern, or for $10 \mathrm{~min}$ if no intromission patterns occurred. Statistical analysis was by Kruskal-Wallis and Mann-Whitney tests.

\section{Results and Discussion}

The Group BLx males were similar to Group Sx males in the number of intromission patterns displayed and in the proportion of these patterns that were verified as insertions by paint on the glans (Table 2). As in Exp. 1, Group ICx males displayed few intromission patterns, and only one of these was verified by paint to have been accompanied by penile insertion.

Table 2. Copulatory behaviour (means \pm s.e.m.) during paint tests in Exp. 2.

\begin{tabular}{lccc}
\hline & $\begin{array}{c}\text { No. of } \\
\text { rats }\end{array}$ & $\begin{array}{c}\text { Intromission } \\
\text { patterns }\end{array}$ & $\begin{array}{c}\text { Confirmed } \\
\text { insertions }\end{array}$ \\
\hline Group BLx & 6 & $12 \cdot 2 \pm 1 \cdot 0$ & $11 \cdot 3 \pm 1 \cdot 3$ \\
Group ICx & 8 & $3 \cdot 2 \pm 1 \cdot 1^{*}$ & $0 \cdot 1 \pm 0 \cdot 1^{*}$ \\
Group Sx & 8 & $15 \cdot 1 \pm 2 \cdot 3$ & $13 \cdot 2 \pm 2 \cdot 1$ \\
\hline
\end{tabular}

* $P<0.001$ relative to Groups BLx and Sx by Mann-Whitney test. 
The results support the conclusions from Exp. 1 that the bulbocavernosus and levator ani muscles are not necessary for the normal occurrence of vaginal penetration and the accompanying skeletal movements. In contrast, absence of the ischiocavernosus muscles and crurae effectively precludes normal copulation by sharply reducing the potential for intromission.

\section{Experiment 3}

In Exps 1 and 2 the crurae underlying the ischiocavernosus muscles had been removed along with the muscles. Excision of the crurae eliminated or curtailed the normal blood supply to the corpus cavernosum, and removed the anchor of the penis to the pelvic bone. To isolate the specific contributions of these muscles, in this experiment the ischiocavernosus muscles were removed without damaging the crurae.

\section{Materials and Methods}

The 8 sham-operated animals from Exps 1 and 2 were used. Five of the males (Group Ix) were randomly selected for surgical removal of the ischiocavernosus muscles approximately 5 days after the end of Exp. 2. All aspects of the surgery were as in Exp. 1, except that only a midline incision was made and the fascicles of muscle were carefully cut and stripped away from the crura without damaging it. One male died after surgery. In the control males (Group $\mathrm{Sx}, \mathrm{N}=3$ ) the ischiocavernosus muscles were exposed but not damaged before closing the incision.

Beginning 10 days after surgery the males received 2 standard copulation tests, 3 penile reflex tests, and a copulation paint test as in Exp. 2. Successive tests were given on alternate days. These tests were conducted as in the preceding experiments. As in Exp. 1 only the second copulation test and the second reflex test, as well as the paint test, were used for data analysis.

\section{Results}

Males in Group Ix did not differ significantly from the Group Sx males in the number of erections (Table 3), but they displayed significantly fewer cups (in fact, none in any of the 3 tests) and flips.

During the second copulation test, only 2 of the Group Ix males displayed the ejaculatory pattern. The 2 non-ejaculating males had only 6 and 4 intromission patterns in 55 and 66 mounts, respectively, before the test was terminated $30 \mathrm{~min}$ after the first intromission pattern. The other two males in Group Ix ejaculated after 25 and 11 intromission patterns, respectively, compared with 7, 7, and 8 pre-ejaculatory intromission patterns for the Group Sx males $(P<$ $0 \cdot 10$, one-tailed $t$ test, not significant).

Table 3. Penile reflexes and copulatory behaviour in the paint test following excision of $\mathrm{m}$. ischiocavernosus (Group $\mathrm{Ix}, \mathrm{N}=4$ ) or sham operations (Group $\mathrm{Sx}, \mathrm{N}=3$ )

\begin{tabular}{|c|c|c|c|c|c|}
\hline & \multicolumn{3}{|c|}{ Reflex test } & \multicolumn{2}{|c|}{ Paint test } \\
\hline & Erections & Cups & Flips & $\begin{array}{l}\text { Intromission } \\
\text { patterns }\end{array}$ & $\begin{array}{l}\text { Confirmed } \\
\text { insertions }\end{array}$ \\
\hline Group Ix & $13 \cdot 2 \pm 4 \cdot 6$ & $0.0 \pm 0.0^{*}$ & $1 \cdot 2 \pm 1 \cdot 0^{*}$ & $10 \cdot 8 \pm 2 \cdot 1$ & $1.8 \pm 0.8^{*}$ \\
\hline Group Sx & $14.0 \pm 3.0$ & $8.0 \pm 3.2$ & $16 \cdot 0 \pm 6 \cdot 1$ & $10 \cdot 7 \pm 1.9$ & $10.7 \pm 1.9$ \\
\hline
\end{tabular}


In the copulation paint test the Group Ix males were similar to the Group Sx males in the number of intromission patterns displayed, but penile insertion occurred only in a small proportion (Table 3). Nonetheless, 3 of the 4 males in Group Ix displayed the ejaculatory pattern. However, the ejaculation of 2 of these males was clearly extravaginal (confirmed by a seminal plug far from the vagina), and 1 of these males had no confirmed insertions among his 17 pre-ejaculatory intromission patterns.

\section{Discussion}

This experiment confirmed an essential role for the ischiocavernosus muscles in copulation. Without these muscles, rats displayed the intromission pattern in only a small proportion of their mounts, and only a very small proportion of these intromission patterns were actually accompanied by penile insertion. Observation of many of the extravaginal intromission patterns indicated that, during these patterns, the glans penis was fully extended beyond the sheath, but along the thigh or ventral surface of the female rather than inside the vagina. This penile elongation was similar to the extravaginal intromission patterns seen in intact males (Pollak \& Sachs, 1976), as well as to the ex copula elongated (long) flips of spinal male rats (Hart, 1968). These observations suggest that the ischiocavernosus muscles effect short flips ex copula, which are probably comparable in copula to the pre-insertion dorsiflexion of the glans. However, the ischiocavernosus muscles may not contribute to the full elongation of the glans during intromission or to elongated flips ex copula.

Although the probability of ejaculation was reduced by removal of the ischiocavernosus muscles, several of the males did ejaculate, indicating that these muscles are not necessary for ejaculation. The ejaculations often followed an unusually large number of (extravaginal) intromission patterns, but in the paint test 2 males ejaculated after 9 intromission patterns, and in each case only 3 of the patterns were revealed by paint to have been accompanied by insertion. The ability of these operated males to attain ejaculatory excitation with only rare intromission is noteworthy. Potential stimulation of the penis from the female's fur cannot be ruled out, although there was often no apparent contact between the glans and the female. Alternatively, ejaculatory excitation may have derived from mutual stimulation of the glans and the penile sheath. A potential role for such stimulation in accumulating ejaculatory potential was first inferred from the fact that circumcised rats have a higher number of intromissions before ejaculation than do normal rats (Lumia, Sachs \& Meisel, 1979).

In Exp. 1, males from which the ischiocavernosus muscles and the crurae had been removed displayed an undiminished number of penile cups ex copula. In contrast, the Group Ix males in Exp. 3, with intact crurae, displayed no cups at all. We cannot offer a confident explanation for this reduced potential for intense erection resulting from sparing of a major penile anchor and blood conduit.

\section{Experiment 4}

During the paint test in Exp. 2, it appeared that there might be a difference amongst males in the size of the ejaculatory plug, i.e. when the glandes were inspected for paint after the ejaculatory pattern, the seminal plug adhering to the glans of control males was generally smaller than that of the Group BLx males. Experiment 4 was conducted to test this impression empirically, and to determine whether this difference in plug size was associated with a difference in the males' potential for inducing pregnancy in females.

\section{Materials and Methods}

The animals were 6 males from Exp. 1 (Group BLx, bulbocavernosus and levator ani muscles removed), and 8 intact control males excluded from Exp. 1 because of inadequate performance 
in ex copula reflex tests. (Testing began approximately 2 months after Exp. 1.) Normal cyclic females were screened for oestrus by manual flank and perineal stimulation; those displaying signs of receptivity were placed in a test cage with the subject males. Females not displaying good lordosis when mounted by the males were replaced by other females, unless the male had displayed an intromission pattern, in which the case the male was retested on another day with another female.

If the female was adequately receptive, copulation was uninterrupted until the male displayed the ejaculatory pattern. Immediately after dismount and before any genital grooming occurred, the male was removed from the cage, and all coagulated seminal material adhering to the glans was removed with toothed forceps and weighed to the nearest $\mathrm{mg}$ on an electronic balance. The mated female was left undisturbed for at least $5 \mathrm{~min}$ and was then returned to her cage.

Each experimental male was tested 3 times and each control male once or twice. Due to failures of males or females to mate in given tests and due to extravaginal ejaculations detected when the female was inspected after $5 \mathrm{~min}$, some test data could not be used. Experimental males contributed $1-3$ datum points and control males $0-2$.

Mated females were killed 20 days after copulation to count the fetuses, inspect the uteri for aborted fetuses, and grossly inspect the ovaries.

\section{Results}

The median weight of seminal material adhering to the glans of experimental males was almost 4 times heavier than that of control males, and there was little overlap between the groups $(t(12)=$ $3.81, P<0.01$; Text-fig. 1). Microscopic inspection of some of the plug material adhering to experimental males revealed normal motile spermatozoa. The mean $( \pm$ s.e.m.) number of pre-ejaculatory intromission patterns displayed by experimental $(8.08 \pm 0.74)$ and control $(7.50 \pm 0.65)$ males did not differ significantly $(t=0.59)$. Of the 10 females mated to control males, 6 were pregnant, whereas only 1 of 15 females mated with experimental males was

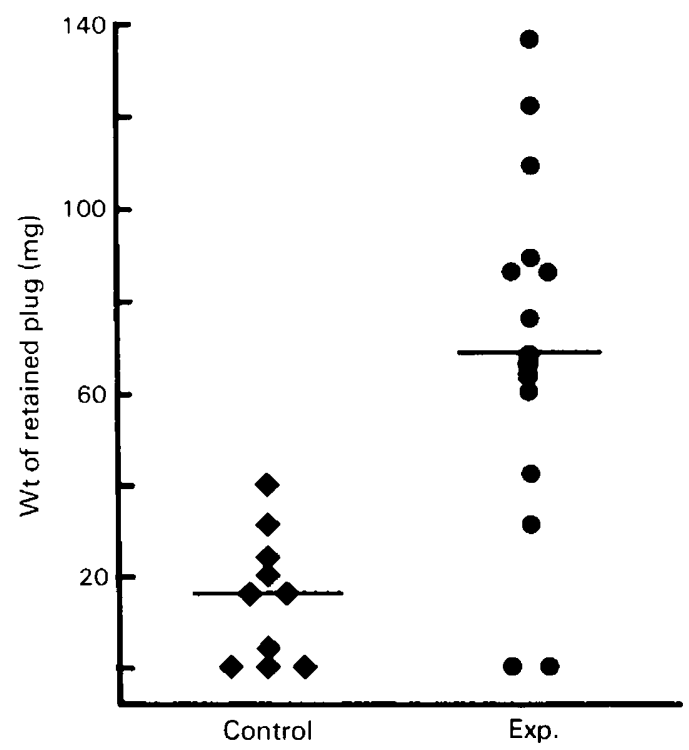

Text-fig. 1. Weights of the retained portion of the seminal plug after ejaculation by control rats or experimental (Exp.) rats with excised bulbocavernosus and levator ani muscles. Each point represents a separate plug. Lines indicate means. 
pregnant $(P=0.01$, Fisher exact probability test). The uteri of non-pregnant females revealed no implantation sites, and the ovaries appeared to be cyclic, with ripening and mature follicles.

\section{Discussion}

Removal of the bulbocavernosus and sphincter ani muscles of male rats rendered them virtually infertile. Males displayed a normal number of pre-ejaculatory intromission patterns and deposited some seminal material with motile spermatozoa into the females, but they retained more plug material than did intact males. This difference in plug retention is, we believe, the key to the difference in fertility, although differences in size of plug and sperm count cannot be ruled out as contributory factors.

To become pregnant, female rats need several elements in addition to a complement of spermatozoa. They need to experience an adequate number of penile intromissions spaced at appropriate intervals for induction of a progestational state (reviewed by Adler, 1978). The ejaculated plug also needs to be deposited firmly against the cervix to potentiate entry of spermatozoa into the uterus and to facilitate sperm transport (Blandau, 1945; Matthews \& Adler, 1978). The number of intromissions and the other copulatory measures of the experimental males were similar to those of controls, so that at least some of the females may have been made pseudopregnant. However, the larger plug retained by experimental males suggests that fewer spermatozoa may have been available within the uterus. The greater retention of the plug by experimental males is probably due to the inability of these males to form a penile cup (Exp. 1). This structure is believed to be necessary and sufficient for inducing pseudopregnancy in mice, but not in rats (McGill, 1977). Some modification of this conclusion may be necessary. When the male rat ejaculates, the cup forms at or just before the time of maximum penile extension, and just before the plug leaves the urethral meatus (Pollak \& Sachs, 1976). The timing and configuration of the cup make it ideal for exposing the cervical lumina, pushing the plug firmly against, and partly through, the cervix, and leaving the plug in place there (Blandau, 1945; Pollak \& Sachs, 1976; Matthews \& Adler, 1978). If the cup were unable to form, the glans would continue to grip the coagulated plug, withdrawing a larger portion of its proximal end from the vagina, and possibly dislodging its distal end from the cervix.

It is also likely that at least some of the females mated to experimental males did not become pseudopregnant, despite receiving enough intromissions to have induced the progestational state under normal conditions (Edmonds, Zoloth \& Adler, 1972). It had been reported (Pollak \& Sachs, 1976) that during extravaginal intromission patterns the glans penis is fully extended but not distended, whereas during extravaginal ejaculation penile extension is accompanied by distension and formation of the cup. Re-examination of the videotapes analysed by Pollak \& Sachs (1976) has now revealed ( 3 independent observers) that the glans also becomes distended during intromission patterns to the extent that partial cups were formed in at least 3 of the 5 clearest extravaginal intromission patterns. These cups appeared to be less complete than those occurring during ejaculations, and they may not have qualified as cups in ex copula tests, but the resolution of the rapidly moving glans on videotape was inadequate to quantify the degree of dilatation of the distal glans.

It seems safe to assume that experimental males had less distension of the glans than normal males during intromissions. One consequence of reduced erection would be reduced stimulation of the vaginal wall. This reduction would be especially marked if one effect of penile erection is not just to increase the diameter of the glans, but also to erect the papillae.

This hypothesis is consistent with the interpretation of Baumgardner \& Dewsbury (1980) that oestradiol-treated castrated rats are relatively ineffective in inducing the progestational state because of post-castration changes in penile morphology. These authors focussed on the size of the penis and its spines. To these variables we may now add that without the trophic action of androgen on the penile muscles, the rats would still insert during copulation (O'Hanlon et al., 1981), but there would be reduced erection and therefore less stimulation of the vagina. 


\section{General Discussion}

These studies have established several distinct roles for the rat's striated penile muscles in effecting penile actions, copulation and pregnancy. Specifically, the ischiocavernosus muscles appear to have their major role in extending the penis from its normal flexed position. This action is seen externally as short dorsiflexive flips of the glans in ex copula reflex tests, and apparently permits vaginal penetration during copulation by straightening out the penis so that it is directed at the vagina during thrusting. In the absence of these muscles, erections and cups are seen $e x$ copula (Exp. 1), and intromission patterns may occur in mating tests, but the fully extended penis usually is outside the vagina (Exps 2 and 3). The full elongation of the glans penis during intromission patterns may be comparable to the long flips seen in ex copula tests, and its occurrence in copula in males lacking ischiocavernosus muscles suggests that these muscles are not responsible for elongated flips. It remains to be determined whether elongation of the glans is due to the action of other muscles or to vascular action.

The bulbocavernosus and/or levator ani muscles apparently have their major role in effecting erection, especially the intense erections in which a penile cup is formed (Exp. 1). The ability of males to have partial erections even when these muscles are removed suggests that other (vascular or smooth muscle) mechanisms can effect erection, and that, in rodents as in some other mammalian groups, contractions of the penile muscles are co-ordinated with and augment vascular contributions to erection (Purohit \& Beckett, 1976; Hart, 1983). Such motor co-ordination implies a virtual synchronization of autonomic and somatic neural efferents.

Males lacking the ischiocavernosus or the bulbocavernosus and levator ani muscles were capable of ejaculating a seminal plug. Thus, none of these muscles is indispensable for ejaculation in rats, although they are likely to be active during ejaculation due to their functions in copulation, and they may have a contributory role in ejaculation just as they appear to in some other mammals (e.g. Purohit \& Beckett, 1976).

Males without their bulbocavernosus and levator ani muscles displayed copulatory behaviour that appeared normal (Exps 1, 2, and 4), but these males were severely impaired in their ability to impregnate females (Exp. 4). Their handicap did not result from an inability to ejaculate, but from a reduced capacity for erection, resulting in, presumably, less vaginal stimulation of the female and in suboptimal deposition of the seminal plug. Sexual potency and ultimate fertility of male rats therefore depend on co-ordination of the penile muscles with each other, with autonomic effectors, with other skeletal actions such as hip flexion and extension (e.g. Pollak \& Sachs, 1976), and with the postures and movements of the female (Adler, Davis \& Komisaruk, 1977; Beyer, Velázquez, Larsson \& Contreras, 1980; Noble, 1980).

Linda Talalas contributed invaluably to the inception and progress of these studies. Linda Miller and Heidi Stuhr provided excellent technical assistance. Many open discussions with Benjamin Hart, who was doing related experiments concurrently, helped me escape some pitfalls and avoid others. This research was supported by NICHHD research grant HD-08933.

\section{References}

Adler, N.T. (1978) Social and environmental control of reproductive processes in animals. In Sex and Behavior, pp. 115-160. Eds T. E. McGill, D. A. Dewsbury \& B. D. Sachs. Plenum Press, New York.

Adler, N.T., Davis, P.G. \& Komisaruk, B.R. (1977) Variation in the size and sensitivity of a genital sensory field in relation to the estrous cycle in rats. Horm. Behav. 9, 334-344.
Baumgardner, D.J. \& Dewsbury, D.A. (1980) Pseudopregnancy in female rats: effects of hormonal manipulations of the male. Physiol. Behav. 24, 693-697.

Beckett, S.D., Hudson, R.S., Walker, D.F., Vachon, R.I. \& Reynolds, T.M. (1972) Corpus cavernosum penis pressure and external penile muscle activity during erection in the goat. Biol. Reprod. 7, 359-364. 
Beckett, S.D., Hudson, R.S., Walker, D.F., Reynolds, T.M. \& Vachon, R.I. (1973) Blood pressure and penile muscle activity in the stallion during coitus. Am. J. Physiol. 225, 1072-1075.

Beckett, S.D., Walker, D.F., Hudson, R.S., Reynolds, T.M. \& Vachon, R.I. (1974) Corpus cavernosum penis pressure and penile muscle activity in the bull during coitus. Am. J. vet. Res. 35, 761-764.

Beckett, S.D., Purohit, R.C. \& Reynolds, T.M. (1975) The corpus spongiosum penis pressure and external muscle activity in the goat during coitus. Biol. Reprod. 12, 289-292.

Beyer, C., Velázquez, J., Larsson, K. \& Contreras, J.L. (1980) Androgen regulation of the motor copulatory pattern in the male New Zealand white rabbit. Horm. Behav. 14, 179-190.

Blandau, R.J. (1945) On the factors involved in sperm transport through the cervix uteri of the albino rat. Am. J. Anat. 77, 253-272.

Breedlove, S.M. \& Arnold, A.P. (1980) Hormone accumulation in a sexually dimorphic motor nucleus of the rat spinal cord. Science, N.Y. 210, 564-566.

Breedlove, S.M. \& Arnold, A.P. (1981) Sexually dimorphic nucleus in the rat lumbar spinal cord: response to adult hormone manipulation, absence in androgen-insensitive rats. Brain Res. 225, 297 307.

Cinák, R., Gutmann, E. \& Hanzliková, V. (1967) Morphologische, physiologische Merkmale, Entwicklung und Homologie des M. "levator" ani der Ratte. Anat. Anz. 120, 492-506.

Cihák, R., Gutmann, E. \& Hanzliková, V. (1970) Involution and hormone-induced persistence of the $M$. sphincter (levator) ani in female rats. J. Anat. 106, 93-110.

Dail, W.G., Jr \& Evan, A.P., Jr (1974) Experimental evidence indicating that the penis of the rat is innervated by short adrenergic neurons. $A m$. J. Anat. 141, 203-218.

Edmonds, S., Zoloth, S.R. \& Adler, N.T. (1972) Storage of copulatory stimulation in the female rat. Physiol. Behav. 8, 161-164.

Greene, E.C. (1935) Anatomy of the rat. American Philosophical Society, Philadelphia.

Hart, B.L. (1968) Sexual reflexes and mating behavior in the male rat. J. comp. physiol. Psychol. 65, $453-460$.

Hart, B.L. (1972) The action of extrinsic penile muscles during copulation in the male dog. Anat. Rec. 173, $1-6$.

Hart, B.L. (1983) Neurological bases of male sexual behavior: a comparative analysis. In Neurobiology of Reproduction; Handbook of Behavioral Neurobiology, (in press). Eds N. T. Adler \& D. W. Pfaff. Plenum Press, New York.
Hart, B.L. \& Kitchell, R.L. (1966) Penile erection and contraction of penile muscles in the spinal and intact dog. Am. J. Physiol. 210, 257-261.

Hayes, K.J. (1965) The so-called 'levator ani' of the rat. Acta endocr., Copenh. 48, 337-347.

Hebel, R. \& Stromberg, M.W. (1976) Anatomy of the Laboratory Rat. Williams \& Wilkins, Baltimore.

Jordan, D.L., Breedlove, S.M. \& Arnold, A.P. (1982) Sexual dimorphism and the influence of neonatal androgen in the dorsolateral motor nucleus of the rat lumbar spinal cord. Brain Res. (In press).

Lumia, A.L., Sachs, B.D. \& Meisel, R.L. (1979) Sexual reflexes in male rats: restoration by ejaculation following suppression by penile sheath removal. Physiol. Behav. 23, 273-277.

Matthews, M.K., Jr \& Adler, N.T. (1978) Systematic interrelationship of mating, vaginal plug position, and sperm transport in the rat. Physiol. Behav. 20, 303-309.

McConnell, J., Benson, G.S. \& Wood, J. (1979) Autonomic innervation of the mammalian penis: a histo-chemical and physiological study. J. Neural Transmission 45, 227-238.

McGill, T.E. (1977) Reproductive isolation, behavioral genetics, and functions of sexual behavior in rodents. In Reproductive Behavior and Evolution, pp. 73-109. Eds J. S. Rosenblatt \& B. R. Komisaruk. Plenum Press, New York.

Noble, R.G. (1980) Sex responses of the female hamster: effects on male performance. Physiol. Behav. 24, 237-242.

O'Hanlon, J.K., Meisel, R.L. \& Sachs, B.D. (1981) Estradiol maintains castrated male rats' sexual reflexes in copula, but not ex copula. Behav. Neural Biol. 32, 269-273.

Pollak, E.I. \& Sachs, B.D. (1976) Penile movements and the sensory control of copulation in the rat. Behav. Biol. 17, 177-186.

Purohit, R.C. \& Beckett, S.D. (1976) Penile pressures and muscle activity associated with erection and ejaculation in the dog. Am. J. Physiol. 231, 13431348.

Sachs, B.D. \& Barfield, R.J. (1976) Functional analysis of masculine copulatory behavior in the rat. $A d v$. Study Behav. 7, 91-154.

Sachs, B.D. \& Garinello, L.D. (1978) Interaction between penile reflexes and copulation in male rats. $J$. comp. Physiol. Psychol. 92, 759-767.

Schrøder, H.D. (1980) Organization of the motoneurons innervating the pelvic muscles of the male rat. $J$. comp. Neurol. 192, 567-587.

Wainman, P. \& Shipounoff, G.G. (1941) The effects of castration and testosterone propionate on the striated perineal musculature in the rat. Endocrinology 29, 975-978.

Received 15 December 1981 